Canadian Oncology

Nursing Journal

Revue canadienne

de soins infirmiers

en oncologie

Volume 28, Issue 4 • Fall 2018

elSSN: 2368-8076 


\title{
Building and sustaining a postgraduate student network: The experience of oncology nurses in Canada
}

\author{
by Jacqueline Galica, Karine Bilodeau, Fay Strohschein, Tracy L. Powell, Leah K. Lambert, and Tracy L.O. Truant
}

\begin{abstract}
Networking with individuals on a similar journey through graduate studies has been identified as an important influence in the experience of doctoral and postdoctoral students. Through the Board of Directors of the Canadian Association of Nurses in Oncology/Association canadienne des infirmières en oncologie (CANO/ACIO), student members were encouraged to establish a Doctoral Student Network (DSN) that would enable a connection through education and common interest in oncology and cancer care. Since its inception, the DSN has been dynamic in how it has addressed the evolving needs of members and in providing development opportunities to group members. To uncover and describe key aspects of its evolution, a document analysis was undertaken to reveal themes pertaining to capacity development and leadership voice as paths to leadership for DSN members. The results of this study suggest that the DSN provides a supportive environment for postgraduate nurses across Canada to connect with others in their peer group to foster engagement in educational, professional, and scholarly activities, as well as highlighting opportunities for other professional organizations interested in establishing a support network for graduate student members.
\end{abstract}

\section{ABOUT THE AUTHORS}

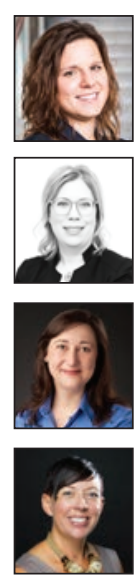

Jacqueline Galica, RN, MSc, PhD, CON(C), Assistant Professor, Queen's University

Karine Bilodeau, RN, PhD, CON(C), Assistant Professor, Université de Montréal

Fay Strohschein, RN, PhD(c), Doctoral Candidate, Ingram School of Nursing, McGill, University

Tracy L. Powell, BScN, RN, MN, PhD Student, School of Nursing, University of Victoria/Associate Professor, Mount Royal University

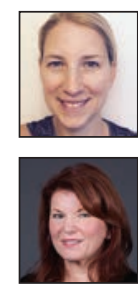

Leah K. Lambert, RN, PhD(c), Doctoral Candidate, School of Nursing, University of British Columbia

Tracy L.O. Truant, RN, MSN, PhD(c), Doctoral Candidate, School of Nursing, University of British Columbia

Corresponding author: Jacqueline Galica, RN, MSc, PhD, CON(C), Assistant, Professor, School of Nursing, Queen's University, 92 Barrie Street, Kingston, Ontario, K7L 3N6

(613)-533-2000 Extension 75122; jacqueline.galica@queensu.ca DOI:10.5737/23688076284288293
Key words: Leadership; nursing; graduate education; peer mentoring; networking; early career development

\section{INTRODUCTION}

$P$ ostgraduate training (e.g., doctoral and postdoctoral programs) has been described as an emotionally intense (Aitchison \& Mowbray, 2013; Cotterall, 2013) and isolating (Janta, Lugosi, \& Brown, 2014) period in an individual's career trajectory. Establishing a professional network by becoming involved with professional organizations is a key aspect (Sweitzer, 2009) in the successful completion of a postgraduate program (Jairam, 2012). Participation in professional organizations during postgraduate training can have a positive impact on an individual's future job satisfaction and goal attainment (Podolny \& Baron, 1997), as well as their overall career success (Hansen, 1999). In addition to personal gains, involving postgraduates in a professional organization enriches the growth and development of the professional body (Gardner \& Barnes, 2007).

Recognizing these benefits, the Canadian Association of Nurses in Oncology/Association canadienne des infirmières en oncologie (CANO/ACIO) established the Doctoral Student Network (DSN) in 2013. The purpose of the DSN is to facilitate the success of oncology nurses engaged in doctoral and postdoctoral studies and to support the integration of academic nursing within the CANO/ACIO. Whereas graduate students often describe their role in national professional associations as being that of an observer (Gardner \& Barnes, 2007), the DSN provides a means for postgraduate trainees to actively engage with the Association and its members through educational, professional, and scholarly activities. For many nurses, postgraduate training involves transitioning from primarily clinical work to an academic setting or formal research leadership role within a cancer care organization. Such transitions involve developing knowledge and skills to actively engage with research at a higher level. The DSN provides support to trainees in negotiating this transition, while providing a means for members to make important contributions to the DSN and CANO/ACIO.

\section{The DSN structure}

Since its formation, the DSN structure, membership, and activities have evolved to meet the needs and objectives of its members, within the context of CANO/ACIO. One example is the change in frequency of DSN meetings, which are held remotely through the Skype platform (Skype, n.d.). Meetings frequency changed from monthly to quarterly where members across Canada continued to connect through Skype (Skype, n.d.) every three months. This change resulted from member-feedback where a schedule more conducive for members enabled increased meeting attendance and more active member engagement. Building on this small, but positive 
change, the DSN members were encouraged to re-evaluate the larger structure and functioning of the DSN and make additional changes that facilitated the growth and success of the network.

In this paper, we provide an overview of a doctoral and postdoctoral students' network initiative. More precisely, we 1) describe the evolution of the CANO/ACIO DSN; 2) highlight key activities of the DSN; and 3) offer recommendations about sustaining a postgraduate student network within a professional association.

\section{METHODS}

First, an electronic survey was sent to each DSN member to collect data that were used to quantitatively describe the DSN member demographics. Second, to provide an overview of the DSN evolution, a qualitative document analysis of DSNdeveloped documentary sources (e.g., minutes, newsletters, and posters) was performed. Document analysis is a systematic procedure for reviewing or evaluating documents (e.g., print and electronic). According to Bowen (2009), this qualitative method requires that data be examined and analysed in order to interpret meaning, gain understanding, and develop empirical knowledge. Document analysis involves: 1) a high level overview of the included documents; 2) a line-by-line identification and extracting of meaningful content, themes, and concepts within the documentary sources; and 3) analyzing and interpreting the extracted data within and across included documentary sources (Bowen, 2009).

A total of 29 documents cumulated between the years 2013 and 2017 were identified. These included consolidating all DSN meeting minutes $(n=24)$, newsletters $(n=3)$, and notes related to scholarly activities (e.g., Terms of Reference, $\mathrm{n}=2$ ) into a single document. This document was uploaded to Google drive as a shared file for DSN members to review. This process enabled members, spanning different locations and time zones across Canada, to collaboratively participate in the data collection and analysis process.

\section{Data analysis}

Descriptive quantitative analysis to describe the DSN was carried out using SPSS version 24 (IBM, 2016). To analyze the consolidated document, we used content analysis to guide this process (Miles, Huberman, \& Saldaña, 2014). The data analysis stage was iterative and included data reduction, data display, conclusion drawing, and verification. Two coding cycles were performed. The first coding cycle identified emerging themes. During this cycle, each author reviewed the materials and individually attributed codes to a segment of data. Memos were written concerning emerging themes and coding frameworks. In the second cycle, the emerging themes and their relationship to each other were displayed in a figure. Discussion among the authors regarding the coded data, and the representations of relationships among the data within the figure, led to clarity and agreement in the results. Scientific rigour was ensured by triangulating data within different types of documents, in addition to intercoder reliability and agreement checks between coders (Miles et al., 2014).

\section{RESULTS}

\section{Characteristics of the DSN}

At the time of the analysis, the DSN comprised $11 \mathrm{mem}$ bers, nine of whom provided demographic information for this project (81.81\% response rate). ${ }^{1}$ All members identified as female, and the majority identified their age as between 30 and 49 years of age. Most DSN members were PhD candidates residing in five Canadian provinces and were associated with five distinct institutions. The detailed characteristics of the DSN are included in Table 1.

\section{Evolution of the CANO/ACIO DSN: A process driven by expanding our voice}

Through our document analysis, we came to understand the growth of the DSN group as a process of expanding our voice (Figure 1). This process of growth occurred across two salient and interrelated domains: capacity development and leadership voice. The development of capacity led to an increase

\begin{tabular}{|c|c|}
\hline \multicolumn{2}{|c|}{ Table 1: Characteristics of the DSN members* } \\
\hline Characteristic & $N(\%)$ \\
\hline Female & $9(100.00)$ \\
\hline \multicolumn{2}{|l|}{ Age } \\
\hline $30-39$ years & $4(44.44)$ \\
\hline $40-49$ years & $4(44.44)$ \\
\hline $50-59$ years & $1(11.11)$ \\
\hline \multicolumn{2}{|l|}{ Role } \\
\hline PhD Student & $3(33.33)$ \\
\hline PhD Candidate & $4(44.44)$ \\
\hline Postdoctoral Fellow & $2(22.22)$ \\
\hline \multicolumn{2}{|l|}{ Province } \\
\hline Alberta & $1(11.11)$ \\
\hline British Columbia & $4(44.44)$ \\
\hline Ontario & $1(11.11)$ \\
\hline Quebec & $2(22.22)$ \\
\hline Saskatchewan & $1(11.11)$ \\
\hline \multicolumn{2}{|l|}{ Institution } \\
\hline McGill University & $2(22.22)$ \\
\hline University of British Columbia & $4(44.44)$ \\
\hline University of Ottawa & $1(11.11)$ \\
\hline University of Sherbrooke & $1(11.11)$ \\
\hline University of Victoria & $1(11.11)$ \\
\hline \multicolumn{2}{|c|}{$\begin{array}{l}\text { *In 2014, a female, PhD candidate in Europe was an active DSN } \\
\text { member. Her data are not included. }\end{array}$} \\
\hline
\end{tabular}

1 It is acknowledged that since the DSN's inception, members have transitioned into and out of the group and that the number of DSN members has fluctuated between 11-13 members per year. 


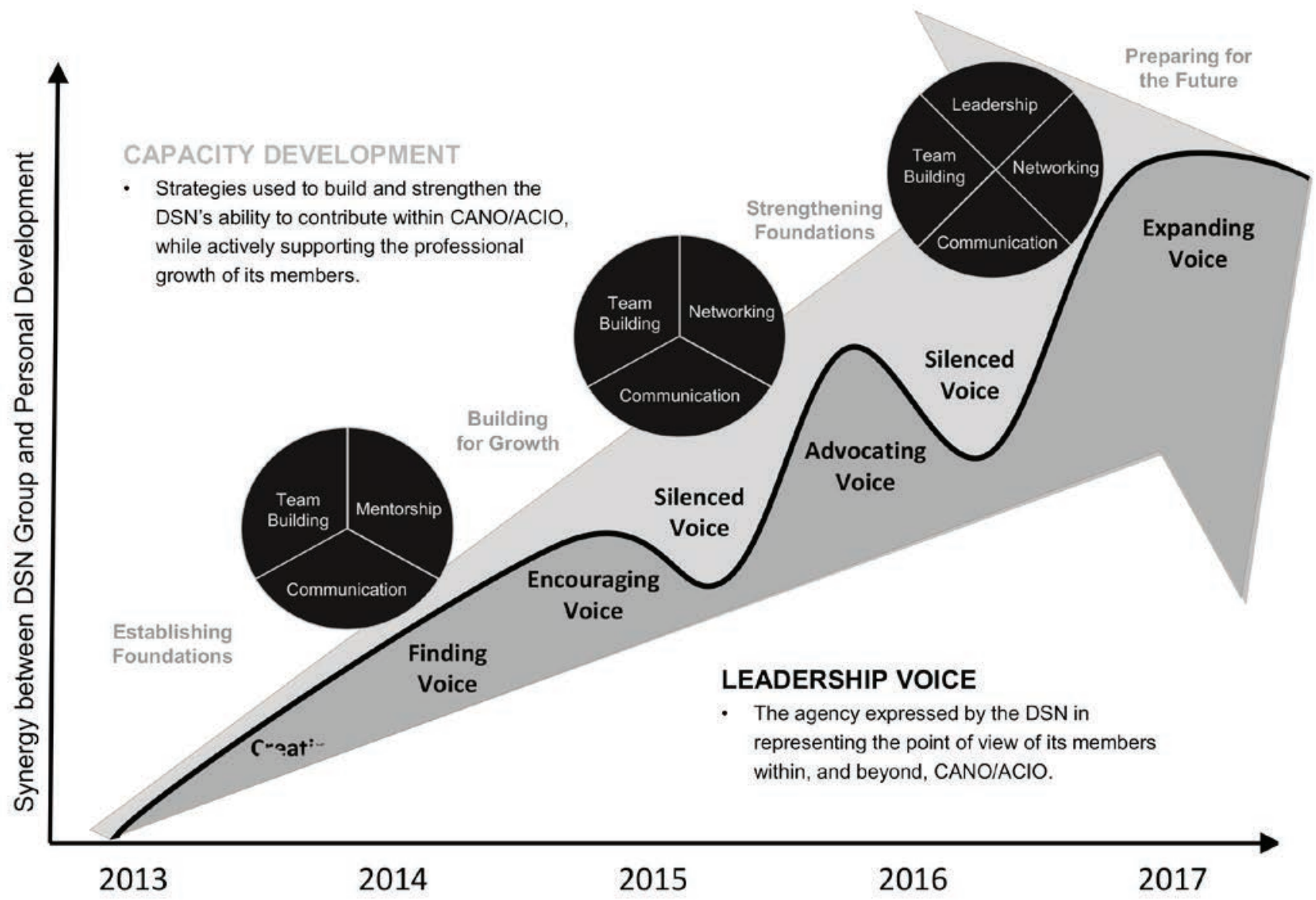

Figure 1. Evolution the CANO/ACIO's DSN: A process driven by expanding our voice

in the group's leadership voice. When the group's leadership voice lessened, strategies to promote capacity development were used to strengthen the group's voice. These domains were influenced by the synergy between DSN development and personal academic development. In the next section, we explain in depth the process of expanding our voice.

Capacity development. This domain refers to the strategies used by the DSN, and particularly by the group's leadership, to build and strengthen the group's ability to contribute within CANO/ACIO, while actively supporting the individual growth of its members. The focus of the capacity development strategies changed over time, from establishing foundations, to building for growth, to strengthening foundations, and finally to preparing for the future. The transition between stages mirrored fluctuations in leadership voice, and contributed overall to expanding the group's voice.

The initial DSN Terms of Reference (TOR) ${ }^{2}$ and meeting notes focused on establishing foundations. The DSN leadership focused on team building and communication strategies that included identifying an appropriate platform for online group meetings, creating a member directory, and developing group webpages on the CANO/ACIO website. Activities

2 The Terms of Reference (TOR) frame the structure of the DSN, specifying accountability and reporting relationships, purpose, membership, and terms of office. for social networking and joint projects, including a CANO/ ACIO workshop, were initiated. The unique voice of the DSN group was reflected in the topic discussion, highlighting the integration of clinical and research perspectives. Establishing foundations also involved establishing a mentorship and accountability structure, through which the group was created as a subcommittee of the CANO/ACIO Research Committee, reporting to the Board of Directors through the Director-atLarge for Research.

The focus then shifted towards building for growth. In this phase, team building and communication strategies remained prominent, while strategies aligned with mentorship shifted toward networking and facilitating professional and social support for doctoral students. The group sought a volunteer to focus on social networking, check-ins with each participating member were continued at the beginning of each Skype (Skype, n.d.) call and strategies for promoting the group at the conference were developed. After the conference, group members completed commentaries for Oncology Exchange (Oncology Exchange, n.d.) and the Canadian Oncology Nursing Journal/Revue canadienne de soins infirmiers en oncologie (Canadian Oncology Nursing Journal/Revue canadienne de soins infirmiers en oncologie, n.d.), again promoting synergy between the development of individual personal and professional goals and the collective group leadership voice. 
In the next phase, the DSN worked to strengthen foundations, by revisiting its Terms of Reference. The scope of the group was expanded to include postdoctoral students and novice doctorally-prepared scholars, and roles within the group that had been difficult to fill (e.g., social networking volunteer) were removed. Contributions to CANO/ACIO were prominent for this phase, as members received a CANO/ACIO poster award at the International Society of Nurses in Cancer Care (ISNCC) conference in Vancouver. As well, DSN members were invited by the CONJ editor to provide input regarding the direction of the journal and the group's involvement as scholars.

Preparing for the future, the current phase of capacity development, is focused on reaching out to new members, while promoting the diversity and longevity of the DSN. A DSN newsletter was initiated and discussion focused on succession planning for the chair role. Strategies to increase group membership included contacting Canadian nursing faculty who work in oncology to aid in the recruitment of new members, using Sosido ("Sosido Networks," n.d.) to ask questions relevant to postgraduate trainee issues, and circulating information related to the DSN in CANO/ACIO member emails.

Leadership voice. The second domain that became evident in the data was that of leadership development. Within this, the theme of leadership voice was revealed as most meaningful when: (a) there was tension between group, personal, and academic commitments; (b) there was collaboration between group and personal capacity development; and (c) DSN capacity was developed, enhanced, or promoted.

The expression of leadership voice was first evident when DSN members became engaged with each other, as the network developed. During this key phase of the DSN, and when the group demonstrated strategies for capacity development over the years, leadership voice was seen as being purposeful and supportive (e.g., 'creating voice' or 'finding voice') through a growth in their synergy. This was highlighted during the development of the DSN Terms of Reference when the newly formed DSN began determining how they would connect with other CANO/ACIO members who met the DSN criteria and when roles and responsibilities of individual DSN members were discussed. Leadership voice continued in the data with 'finding voice' most evident when the DSN established their meeting platform and the process and frequency of group contact. In the data, this theme was repeatedly revealed when the Terms of Reference were revisited, and in anticipation of the calls for CANO/ACIO conference abstract submissions where the group negotiated how they wanted to 'create voice' within the larger CANO/ACIO community at conferences.

The DSN's leadership voice was most effective during times of increased synergy between group and personal capacity. During these phases, 'encouraging', 'advocating', and 'expanding' voice within the DSN was demonstrated as the group sought to enhance their capacity and facilitate growth in the group and individually among members. Support and encouragement of individual members of the DSN was a key aspect noted in the data. The data revealed common aspects of 'encouraging voice' of individual members, and also more broadly to encourage the voice of the DSN. The collaborative components of the group to support the established goals for CANO/ACIO abstract submissions was highlighted in this theme. The subtheme of 'expanding voice' was revealed in the data when the DSN community of practice identified needs, including the addition of post-doctoral fellows in the network.

Overall, the function and capacity of the leadership voice of the DSN was strong and positive, however, a less constructive leadership voice was also noted in the documents as well. Often identified during times of personal and academic pressures, the added strain of committing to the DSN often resulted in a 'silence' in the leadership voice that was revealed as a delay or cancellation of scheduled meetings. Although the 'silence' varied in length of time, these periods were often followed by productive and synergistic phases for the group.

\section{Synergy between DSN Group and Personal Development} Synergy between DSN development and personal academic development. In both domains, growth occurred over time and was greatest when there was a clear synergy between DSN development and personal academic development. There was an alternating synergy and tension between group and personal commitments and capacity development. When tension between group and personal commitments was greatest, the leadership voice was silenced. This tension was evident when the administrative demands and challenges of the DSN group conflicted, both time-wise and energy-wise, with the demands of our own academic programs. For example, when the group was defining roles and looking for volunteers to fill those roles, the tension between group needs and personal academic commitments was clear. At these times, group leaders actively used capacity development strategies to encourage ongoing growth.

When there was a clear synergy between group and personal capacity development, the leadership voice became louder. This synergy was most evident when DSN members collaborated on projects that were aligned with our own academic growth and goals, which also contributed to the group development and contribution to CANO/ACIO. For example, preparation of a CANO/ACIO presentation or workshop or co-authoring a publication strengthened our academic skills and personal curriculum vitae, while also expanding the leadership voice of the DSN group. These and other DSN activities created a safe environment for us to develop and "try out" our leadership and academic skills. These capacity development strategies effectively led to both personal skill development and tangible contributions to CANO/ACIO.

This tension and synergy reflected an individual tension and synergy expressed by group members. In the documents, group members described both tension and synergy across the following domains: group administration and academic commitments, research activities and clinical or service activities, group development and personal/professional development, contributing to $\mathrm{CANO} / \mathrm{ACIO}$, and developing academic skills. 


\section{DISCUSSION}

To our knowledge, this is the first time a postgraduate group of nurses, within a specialty professional association, has described and published their collective professional capacity-building and leadership development process. Our document analysis provided interesting perspectives on how an individual's leadership capacity is challenged by participating in the DSN. Leadership is an essential competency to develop and consolidate in working towards an academic and research career. Participating in a professional postgraduate group also helps to develop professional autonomy. Furthermore, participation in this DSN enhanced the development of research careers for the participants. The National Institute for Health Research suggests that young researchers build a support network (e.g., being part of wider research community), build one's Curriculum Vitae (e.g., publish articles and deliver scientific presentations), and develop a skill set to help them succeed in research including tenacity, a willingness to learn from critique, networking abilities, curiosity, clinical experience, ability to lead projects, and ambition and courage (National Institute for Health Research, 2018). Our results show that participation within the DSN enhances confidence and capacity to initiate scientific and academic activities, such as submitting abstracts to national conferences, delivering workshops, and facilitating interactive poster sessions.

Our results highlight the evolution of the DSN leadership despite tension between group and personal commitments. How has the DSN persisted over time? One hypothesis is the effect of peer mentoring. The DSN brought together oncology nurses engaged in doctoral and postdoctoral studies. A strong common thread was present: oncology nursing research. A recent systematic review points out that mentoring contributed to increasing scientific productivity, to leadership knowledge and skills, improved health and well-being, as well as enhanced culture of collaboration (Hafsteinsdóttir, van der Zwaag, \& Schuurmans, 2017). More precisely, peer mentoring is a valuable source of moral support and peers can provide advice on balancing personal and professional responsibilities, which can enhance personal and professional growth (Bynum, 2015). Sharing the unique experience of being a postgraduate trainee with a group of peers experiencing the same or similar challenges proved to be a source of valuable support and one of the group's greatest strengths.

Our results illustrate the struggle members sometimes face in contributing to group activities. Doctoral and postdoctoral studies involve a fluctuating workload and intensity that changes depending on academic (e.g., doctoral exams, thesis writing, grant writing), professional (e.g., nursing employment), and family (e.g., caring for young children) responsibilities. These were challenging issues for the group that necessitated adjustments to group functioning (e.g., frequency of meetings). An additional obstacle which needed creativity to overcome was that DSN members represented five Canadian provinces, and for a period (2014), one foreign country. The virtual meeting format of the DSN enabled engagement of a diverse group of participants from different geographical areas and time zones. This was an important opportunity to bring together a peer group that might not have been able to connect otherwise due to geographical and time zone differences.

In our analysis, we sought to identify "winning ingredients" that could explain the DSN success. One important factor was the presence of an engaged leader. The DSN had two chairs since 2013, each who coordinated the DSN activities. Another factor that contributed to group synergy was that each DSN member was also a member of CANO/ACIO. Being members of both groups provided a common ground from which to identify and establish ways to engage with the larger CANO/ ACIO organization. Finally, a key ingredient to the group's success was the process of collaborating on projects and initiatives, which served to build greater linkages among participants. These projects enhanced the development of cohesion in the group and advanced the professional development of group members. Table 2 presents recommendations to support a sustainable postgraduate student network.

\section{Strengths and limitations}

One strength of this project is the use of document analysis. This method ensured a structure to our project and ensure scientific rigour. To our knowledge, it is the first time that a student network is analyzed in depth. It should be noted that the project did not seek ethical approval, as data were publicly accessible and did not contain sensitive information. Also, all persons involved in the data analyzed were DSN members and, therefore, their own experience of participating in the network influenced the data analysis. Future research collecting the perspectives of all group members would add further insight into this area of study. A further note, our results document the specific context of a Canadian oncology nurses group.

\section{Table 2: Recommendations to sustain a postgraduate student} network

Recommendations

- Find a common thread in the group (e.g., oncology nursing research)

- Establish an activities coordinator (e.g., president, chair)

- Plan meetings depending on participants' agenda (e.g., Doodlepoll)

- Discuss and adapt group functioning (e.g., frequency of meetings)

- Use the most appropriate communication tool (e.g., Skype, Adobe connect)

- Consider different time zones

- Plan at least one group project each year (e.g., abstract submission, workshop)

- Create an "open climate" to share personal experience

- Align postgraduate student network activities with the association's strategic plan

- Have a communications and marketing plan to enhance the publicity of the group. This is useful strategy for recruitment of new members

- Expand membership to include PhD-prepared new faculty and/ or clinician scientists. 


\section{Conclusion}

CANO/ACIO's DSN provides a supportive environment for doctoral and postdoctoral students, while encouraging these emerging oncology nurse researchers to integrate CANO/ACIO into their professional lives. The networking and supportive format of the DSN may provide an important template for other professional groups within CANO/ ACIO and beyond to achieve their scholarly and professional goals. Looking to the future, the DSN may use their strengthened capacity and expanding leadership voice as an important resource to further CANO/ACIO's membership development and strategic plan.

More generally, our results contribute to understanding the value of professional networking in the early career stages. The description of the DSN includes the possibility for postgraduate students to engage in a professional network. Key features seem to be essential to develop and ensure sustainability of a postgraduate network: professional or academic

\section{REFERENCES}

Aitchison, C., \& Mowbray, S. (2013). Doctoral women: Managing emotions, managing doctoral studies. Teaching in Higher Education, 18(8), 859-870. doi:10.1080/13562517.2013.827642

Bowen, G.A. (2009). Document Analysis as a qualitative research method. Qualitative Research Journal, 9(2), 27-40. doi:10.3316/ QRJ0902027

Bynum, Y.P. (2015). The power of informal mentoring. Education, 136(1), 69-73.

Canadian Oncology Nursing Journal/Revue canadienne de soins infirmiers en oncologie. (n.d.). Canadian Oncology Nursing Journal/Revue canadienne de soins infirmiers en oncologie. Retrieved from http://www.canadianoncologynursingjournal.com/index. $\mathrm{php} / \mathrm{conj}$

Cotterall, S. (2013). More than just a brain: Emotions and the doctoral experience. Higher Education Research \& Development, 32(2), 174187. doi:10.1080/07294360.2012.680017

Gardner, S.K., \& Barnes, B.J. (2007). Graduate student involvement: Socialization for the professional role. Journal of College Student Development, 48(4), 369-387.

Hafsteinsdóttir, T.B., van der Zwaag, A.M., \& Schuurmans, M.J. (2017). Leadership mentoring in nursing research, career development and scholarly productivity: A systematic review. International Journal of Nursing Studies, 75, 21-34. doi:10.1016/j. ijnurstu.2017.07.004

Hansen, M.T. (1999). The search-transfer problem: The role of weak ties in sharing knowledge across organization subunits. Administrative Science Quarterly, 44(1), 82. doi:10.2307/2667032

IBM. (2016). IBM SPSS Statistics 24 Brief Guide. ( I. B. M., Ed.). Retrieved from http://ftp://public.dhe.ibm.com/software/ analytics/spss/documentation/statistics/24.0/en/client/Manuals/ IBM_SPSS_Statistics_Brief_Guide.pdf organization/association endorsement, strong engagement on a topic/theme, and group reflexivity. Our results also show that this type of network can persist over years and can gain autonomy. The sustainability of the network continues to be an important issue to address on an ongoing basis. More research is needed to better understand how postgraduate trainee leadership can be developed and enhanced though a postgraduate network. Qualitative interviews seem to be an interesting starting point to explore leadership capacity among network participants. A strengths, weaknesses, opportunities and threats (SWOT) analysis (Pearce, 2007) can be used to determine how leadership impacts a student network in terms of strengths, weaknesses, opportunities, and threats. Finally, a postgraduate students' network is a great initiative to stimulate leadership development and to offer peer-mentoring opportunities as well as to consolidate competencies needed to build a successful academic career.

Jairam, D. (2012). Navigating the doctoral experience: The role of social support in successful degree completion. International Journal of Doctoral Studies, 7, 311-329.

Janta, H., Lugosi, P., \& Brown, L. (2014). Coping with loneliness: A netnographic study of doctoral students. Journal of Further and Higher Education, 38(4), 553-571. doi:10.1080/03098 77X.2012.726972

Miles, M.B., Huberman, A.M., \& Saldaña, J. (2014). Qualitative data analysis: A methods sourcebook. Thousand Oaks: SAGE.

National Institute for Health Research. (2018). Building a research career: A guide for aspiring clinical academics and their managers. (National Institute for Health Research, Ed.). UK: NHS. Retrieved from https://www.nihr.ac.uk/our-faculty/documents/Building-aresearch-career-handbook.pdf

Oncology Exchange. (n.d.). Oncology exchange. Retrieved from http:// www.oncologyex.com/

Pearce, C. (2007). Ten steps to carrying out a SWOT analysis. Nursing Management, 14(2).

Podolny, J.M., \& Baron, J.N. (1997). Resources and relationships: social networks and mobility in the workplace. American Sociological Review, 62(5), 673. doi:10.2307/2657354

Skype. (n.d.). Skype. Retrieved February 9, 2018, from https://www. skype.com/en/

Sosido Networks. (n.d.). Retrieved from http://blog.sosido.com/about/

Sweitzer, S. (2009). Towards a theory of doctoral student professional identity development: A developmental networks approach. The Journal of Higher Education, 80(1), 1-33. 